\title{
Laryngeal Responses to Mechanically Assisted Cough in Progressing Amyotrophic Lateral Sclerosis
}

\author{
Tiina M Andersen PT MSc, Astrid Sandnes MD, Ove Fondenes MD, Roy M Nilsen PhD, \\ Ole-Bjørn Tysnes MD PhD, John-Helge Heimdal MD PhD, Hege H Clemm MD PhD, \\ Thomas Halvorsen MD PhD, Maria Vollsæter MD PhD, and Ola D Røksund PT PhD
}

BACKGROUND: Respiratory complications represent the major cause of death in amyotrophic lateral sclerosis (ALS). Noninvasive respiratory support is the mainstay therapy, but treatment becomes challenging as the disease progresses, possibly due to a malfunctioning larynx, which is the entrance to the airways. We studied laryngeal response patterns to mechanically assisted cough (mechanical insufflation-exsufflation) as ALS progresses. METHODS: This prospective longitudinal study of 13 consecutively included subjects with ALS were followed up during 2011-2016 with repeated tests of lung function, neurological status, and laryngeal responses to mechanical insufflation-exsufflation using video-recorded flexible transnasal fiberoptic laryngoscopy. RESULTS: Follow-up time was median 17 (range 6-59) months. In total, 751 laryngoscopy recordings from 67 individual examinations (median 4 per subject, range 2-11 per subject) were analyzed. Adverse laryngeal events that developed with disease progression during insufflation included adduction of true vocal folds in 8 of 9 spinal-onset subjects and adduction of aryepiglottic folds in all subjects, initially at the highest positive pressure and prior to onset of other bulbar symptoms in spinal-onset subjects. As cough became less expulsive with disease progression, laryngeal adduction occurred at lower insufflation pressures. Retroflex movement of the epiglottis was observed in 7 of 13 subjects regardless of insufflation pressures and independent of bulbar involvements. Backward movement of the tongue base occurred regardless of insufflation pressures in all but 1 subject. During exsufflation, constriction of the hypopharynx was observed in all subjects regardless of the presence of bulbar symptoms, after the adverse events that occurred during insufflation. CONCLUSIONS: Applying high insufflation pressures during mechanically assisted cough in ALS can become counterproductive as the disease progresses; importantly also prior to the onset of bulbar symptoms. The application of positive inspiratory pressures should be tailored to the individual patient, and laryngoscopy during ongoing treatment appears to be a feasible tool. Key words: mechanical insufflation-exsufflation; cough augmentation; neuromuscular disease; motor neuron disease; larynx; laryngoscopy. [Respir Care 2018;63(5):538-549. () 2018 Daedalus Enterprises]

\section{Introduction}

Amyotrophic lateral sclerosis (ALS) is a progressive, incurable, and fatal disease caused by loss of motor neu-

\footnotetext{
Ms Andersen and Drs Fondenes and Vollsæter are affiliated with the Norwegian Centre of Excellence for Home Mechanical Ventilation, Thoracic Department, Haukeland University Hospital, Bergen, Norway. Ms Andersen is also affiliated with the Department of Physiotherapy, Haukeland University Hospital, Bergen, Norway. Drs Sandnes, Clemm, Halvorsen, Vollsæter, and Røksund are affiliated with the Department of Pediatrics, Haukeland University Hospital, Bergen, Norway. Dr Tysnes
}

rons in the cortex, brainstem, and spinal cord, eventually resulting in severe global muscle weakness, including respiratory and bulbar innervated muscles. ${ }^{1}$ Treatment is largely symptomatic, and average life expectancy at the 
time of the diagnosis is $2-3$ years unless ventilatory assistance is provided. ${ }^{2}$ Bulbar muscle dysfunction complicates clinical handling of patients with ALS and leads to life-threatening respiratory complications. Of vital importance in this context is impaired cough with accumulation of secretions and pneumonias, as well as choking, laryngospasm, dysarthria, and dysphagia. In about one third of ALS patients the disease has bulbar onset, whereas in patients with spinal onset ALS, bulbar dysfunction presents with disease progression. ${ }^{1}$

A proactive preventive approach applying techniques for assisted cough and noninvasive ventilation (NIV) support is a key element in the management of respiratory complications in ALS. Mechanical insufflation-exsufflation (MI-E) is used to assist cough mechanically by first delivering a positive pressure to facilitate a deep inhalation (insufflation), followed by a negative pressure to assist the expiratory flow during the coughing itself (exsufflation), which facilitates removal of the airway secretions. ${ }^{3}$ Particularly in patients with bulbar symptoms, MI-E is less effective in producing the expiratory cough peak flow considered necessary for effective removal of airway secretions. ${ }^{4,5}$ Moreover, data indicate that NIV may not always be successful in these patients. ${ }^{6-8} \mathrm{We}$ have suggested in a previous a cross-sectional study that these challenges can be linked to the medial collapse of supraglottic laryngeal structures during insufflation, and that modifications of the MI-E settings can be beneficial. ${ }^{9}$

The larynx is the entrance valve to the airway tree. However, laryngeal responses to noninvasive respiratory treatment have never been studied longitudinally as ALS progresses. The aims of this study were to investigate longitudinal changes in the laryngeal responses to MI-E with ALS disease progression and to explore whether MI-E

\footnotetext{
Bergen, Bergen, Norway. Drs Tysnes and Heimdal are affiliated with The Faculty of Medicine, Department of Clinical Medicine, University of Bergen, Bergen, Norway. Drs Nilsen and Røksund are affiliated with The Faculty of Health and Social Sciences, Western Norway University of Applied Sciences, Bergen, Norway.
}

A version of this work was presented by Ms Andersen at the European Respiratory Society Congress held November 9, 2017, in Milan, Italy.

Supplementary material related to this paper is available at http:// www.rcjournal.com.

Ms Andersen discloses a relationship with Phillips. The other authors have no conflicts to disclose.

Correspondence: Tiina Andersen MSc PT, Norwegian Centre of Excellence for Home Mechanical Ventilation, Thoracic Department, Haukeland University Hospital, 5021 Bergen, Norway. E-mail: tiina.andersen@helse-bergen.no.

DOI: $10.4187 /$ respcare. 05924

\section{QUICK LOOK}

\section{Current knowledge}

Respiratory complications are life-threating for patients with amyotrophic lateral sclerosis (ALS), and a proactive preventive approach is a key element in disease management. Noninvasive ventilatory support and mechanically assisted cough are mainstay therapeutic techniques, but these methods become challenging as the disease progresses. Inspiratory collapse of supraglottic laryngeal structures may explain some of these treatment failures.

\section{What this paper contributes to our knowledge}

All subjects, despite the type of disease onset, developed laryngeal collapse during assisted inhalation. This occurred prior to the onset of other bulbar symptoms in the majority of subjects. The highest treatment pressures were the most counterproductive. Individually adjusted pressure settings seemed to prolong the patency of the larynx during mechanically assisted cough and may possibly extend successful use of this technique.

could be more successfully applied with bulbar involvement by altering pressure and flow settings.

\section{Methods}

\section{Study Design and Subjects}

All 20 subjects participating in a cross-sectional, population-based study examining laryngeal response patterns to MI-E in $\mathrm{ALS}^{9}$ were asked to participate in this observational, long-term, follow-up study. Eighteen subjects consented; one declined due to discomfort during the examinations, and one declined due to fatigue. There were 5 dropouts: 2 subjects were tracheostomized and 3 subjects died; hence, 13 subjects were included in the study. The long-term follow-up ran from 2011 to 2016. All data retrieval was performed longitudinally at planned visits to the out-patient clinic until death, tracheostomy, or withdrawal. The study protocol was approved by the Regional Committee for Medical Research Ethics (the registry number for the study 2011/784/Western Norway Regional Committee for Medical and Health Research Ethics). Written informed consent was obtained from all participants.

\section{Neurological Assessment and Definitions}

ALS was diagnosed by experienced neurologists (O-BT or TR) in accordance with revised El Escorial criteria. ${ }^{10,11}$ 
Timing of the ALS debut, or onset of ALS symptoms, was defined by symptoms reported and interpreted at the first consultation. Subjects were classified by mode of symptom onset (ie, spinal or bulbar). Bulbar symptoms were further classified by assessing bulbar signs as progressive bulbar or pseudobulbar, characterized primarily by hypotonic or spastic pareses, respectively. The ALS Functional Rating Scalerevised was applied during follow-up. ${ }^{12}$ Dysphagia was defined using the $100-\mathrm{mL}$ water swallow test. ${ }^{13,14}$

\section{Pulmonary Function and Respiratory Strength}

Slow vital capacity, cough peak flow, maximum inspiratory muscle strength, maximum expiratory muscle strength, and sniff nasal inspiratory pressure were measured at each visit. ${ }^{9}$ Maximum insufflation capacity was measured via an oronasal mask with a respirometer (nSpire Health, Hertford, United Kingdom) after air stacking, and the difference between maximum insufflation capacity and slow vital capacity was calculated. ${ }^{15}$

\section{Video-Recorded Transnasal Fiberoptic Laryngoscopy During MI-E}

Video-recorded transnasal fiberoptic laryngoscopy (ENF-P3; Olympus, Tokyo, Japan) was used to visualize laryngeal response patterns during MI-E (Cough Assist; Respironics, Murrysville, Pennsylvania). We used a standardized MI-E protocol with various combinations of pressures, instructions, and manual thoracic thrust. ${ }^{9,16}$ The data were analyzed as described previously. ${ }^{9}$ A total of 5 laryngeal events were targeted, tested, and defined as adverse and typical bulbar features (Table 1). ${ }^{9}$

On the basis of previous findings, ${ }^{9}$ we explored individually tailored MI-E settings for home treatment during the ALS disease progression when new modalities became available with a new device in 2013 (Cough Assist E70, Respironics). We tested patient-triggered insufflation (on/off) and oscillation (frequency 5 and $10 \mathrm{~Hz}$, amplitude 5 and $10 \mathrm{~cm} \mathrm{H}_{2} \mathrm{O}$ ) along with asymmetric use of pressure settings (positive pressure range +15 to $+40 \mathrm{~cm} \mathrm{H}_{2} \mathrm{O}$ combined with the negative pressure range of -30 to $-40 \mathrm{~cm} \mathrm{H}_{2} \mathrm{O}$ ) and reduced insufflation flow (high, medium, and low). Each individual setting of interest was performed 2-4 times, and the cycle with the best quality was studied retrospectively for laryngeal responses.

\section{Statistical Analyses}

Longitudinal continuous measures were depicted using line plots. The Kaplan-Meier survivor function was used to describe the proportion of subjects free of adverse laryngeal MI-E events in relation to the corresponding timing from their ALS debut, with group differences tested

Table 1. Five Laryngeal Events During MI-E*

\begin{tabular}{|c|c|}
\hline Laryngeal Level & Adverse Laryngeal Response During MI-E \\
\hline \multicolumn{2}{|l|}{ Glottic } \\
\hline True vocal folds & $\begin{array}{l}\text { Adduction of true vocal } \\
\text { folds during } \\
\text { insufflation; } \\
\text { paradoxical } \\
\text { movement of true } \\
\text { vocal folds during } \\
\text { inhalation creating } \\
\text { either a slim glottic } \\
\text { opening or a total } \\
\text { closure of glottis }\end{array}$ \\
\hline
\end{tabular}

Supraglottic
Aryepiglottic
folds

Epiglottis

Hypopharyngeal Tongue base

$\begin{array}{ll}\text { Hypopharynx } & \text { A severe } \\ & \text { hypopharyngeal } \\ & \text { narrowing during } \\ & \text { exsufflation }\end{array}$

\footnotetext{
* Events are defined as adverse and typical bulbar features based on previous findings contrasting what has been described as normal cough. Data from References 9, 30, and 31. MI-E = mechanical insufflation-exsufflation
}

using the log-rank test. ${ }^{17}$ Wilcoxon signed-rank test was used to assess differences in months between ALS debut versus observed events. All statistical analyses were performed using Stata version 14 (StataCorp, College Station, Texas). All $P$ values were 2 -sided and values $<.05$ were considered statistically significant. In-depth methodology descriptions are provided in an online supplement (see the supplementary materials at http://www.rcjournal.com). 
Table 2. Subject Characteristics at Study Inclusion and During Follow-Up

\begin{tabular}{|c|c|c|c|c|c|c|c|c|c|c|c|}
\hline \multirow{2}{*}{$\begin{array}{l}\text { Case } \\
\text { No. }\end{array}$} & \multicolumn{6}{|c|}{ At the Study Inclusion } & \multicolumn{5}{|c|}{ Longitudinal Follow-Up With TFL } \\
\hline & Sex & $\begin{array}{l}\text { ALS Debut } \\
\text { Type }\end{array}$ & Age, y & $\begin{array}{l}\mathrm{BMI}, \\
\mathrm{kg} / \mathrm{m}^{2}\end{array}$ & $\begin{array}{l}\text { Bulbar } \\
\text { Symptoms }\end{array}$ & $\begin{array}{l}\text { Develops Bulbar } \\
\text { Symptoms }\end{array}$ & $\begin{array}{l}\text { Bulbar Type } \\
\text { of ALS }\end{array}$ & $\begin{array}{l}\text { Follow-Up } \\
\text { Time, mo }\end{array}$ & Visits, no. & $\begin{array}{l}\text { Video } \\
\text { Clips, no. }\end{array}$ & $\begin{array}{c}\text { Died/Trach/Censored } \\
\text { After Last TFL }\end{array}$ \\
\hline 1 & $\mathrm{M}$ & $S$ & 66 & 24 & No & Yes & $\mathrm{PB}$ & 26 & 8 & 96 & $\mathrm{~T}$ \\
\hline 2 & M & $\mathrm{S}$ & 61 & 21 & No & Yes & PB & 16 & 2 & 24 & $\mathrm{D}$ \\
\hline 3 & M & S & 71 & 26 & No & Yes & PB & 58 & 11 & 168 & $\mathrm{C}$ \\
\hline 4 & M & $S$ & 74 & 23 & No & Yes & PB & 16 & 4 & 39 & $\mathrm{D}$ \\
\hline 5 & M & $\mathrm{S}$ & 50 & 23 & No & No & ND & 50 & 5 & 58 & $\mathrm{C}$ \\
\hline 6 & $\mathrm{M}$ & S & 73 & 24 & No & Yes & PB & 40 & 9 & 117 & $\mathrm{C}$ \\
\hline 7 & $\mathrm{M}$ & S & 67 & 24 & Yes & Yes & PSB & 59 & 9 & 88 & $\mathrm{C}$ \\
\hline 8 & $\mathrm{~F}$ & S & 62 & 26 & Yes & Yes & PSB/PB & 17 & 4 & 30 & $\mathrm{~T}$ \\
\hline 9 & $\mathrm{~F}$ & S & 83 & 16 & Yes & Yes & PSB/PB & 6 & 2 & 24 & $\mathrm{D}$ \\
\hline 10 & $\mathrm{M}$ & B & 73 & 24 & Yes & Yes & PB & 9 & 2 & 15 & $\mathrm{D}$ \\
\hline 11 & M & B & 72 & 26 & Yes & Yes & $\mathrm{PB}$ & 32 & 7 & 51 & $\mathrm{D}$ \\
\hline 12 & $\mathrm{M}$ & B & 58 & 31 & Yes & Yes & PB & 6 & 2 & 15 & $\mathrm{D}$ \\
\hline 13 & F & B & 62 & 25 & Yes & Yes & PSB & 8 & 2 & 17 & $\mathrm{D}$ \\
\hline $\begin{array}{l}\mathrm{ALS}= \\
\mathrm{BMI}= \\
\mathrm{TFL}= \\
\mathrm{S}=\text { spi } \\
\mathrm{B}=\mathrm{bul} \\
\mathrm{PB}=\mathrm{p} \\
\mathrm{PSB}= \\
\mathrm{D}=\mathrm{di} \\
\mathrm{T}=\text { tra } \\
\mathrm{C}=\mathrm{cen} \\
\mathrm{ND}=\mathrm{n}\end{array}$ & $\begin{array}{l}\text { amyotro } \\
\text { body ma } \\
\text { Transnas } \\
\text { al onse } \\
\text { bar onse } \\
\text { ogressiv } \\
\text { sseudob } \\
\text { d } \\
\text { heoston } \\
\text { sored } \\
\text { o data }\end{array}$ & $\begin{array}{l}\text { hic lateral scleros } \\
\text { ss index } \\
\text { al Fiberoptic Lary! } \\
\text { ebulbar } \\
\text { lbar } \\
\text { ized }\end{array}$ & $\begin{array}{l}\text { is } \\
\text { ggoscopy }\end{array}$ & & & & & & & & \\
\hline
\end{tabular}

\section{Results}

\section{Subject Characteristics and Clinical Development During Disease Progression}

The 13 subjects varied substantially according to ALS subtype and disease progression (Table 2). One subject (case no. 7) had very slowly progressing ALS. At inclusion, 3 of 9 subjects with spinal-onset ALS had already developed bulbar symptoms. Of the remaining 6 spinalonset subjects, 5 developed bulbar symptoms after median 43.5 months from ALS debut, and 1 subject never showed bulbar symptoms. Longitudinal development of findings and functional characteristics during follow-up are presented in Figure 1, with rapidly deteriorating trends for all subjects except for case no. 7 .

\section{Examinations With Transnasal Flexible Laryngoscopy}

A total of 751 video-recorded transnasal fiberoptic laryngoscopy film clips from a total of 67 visits were analyzed from the 13 subjects, with a median of 4 visits (range $2-11)$ per subject. The median individual follow-up time from first examination to last was 17 months (range 6-59). Nine subjects with spinal onset were examined a median of 5 times (range 2-11) and a total of 54 times, with a median follow-up time of 26 (range 6-59) months. Four subjects with bulbar onset were examined a median of 2 times (range 2-7) and a total of 13 times, with a follow-up time of median 9 (range 6-32) months.

\section{Laryngeal Response to MI-E}

Generally, the larynx moved downward during applied insufflation and upward (cranially) during exsufflation. As the diseases progressed, cough at the laryngeal level was observed to become gradually less expulsive and less synchronized during the MI-E, and the laryngeal movements (abduction, adduction and abduction) were observed to become rigid and require more time. This disturbed the synchronization between the laryngeal cough movements and the rapid MI-E cycles. Video 1 illustrates this development for 1 case (see the supplementary materials at http://www. rcjournal.com). Figure 2 illustrates the timing of onset of adverse laryngeal events (adduction during insufflation regardless of laryngeal level and/or hypopharyngeal narrowing during exsufflation) in relation to the onset of clinical symptoms that indicated bulbar involvement during the disease progression. Adverse laryngeal response patterns developed before the onset of other bulbar symptoms in most subjects. Table 3 lists subjects' clinical characteristics at the first and last examination as well as at the time when the adverse 

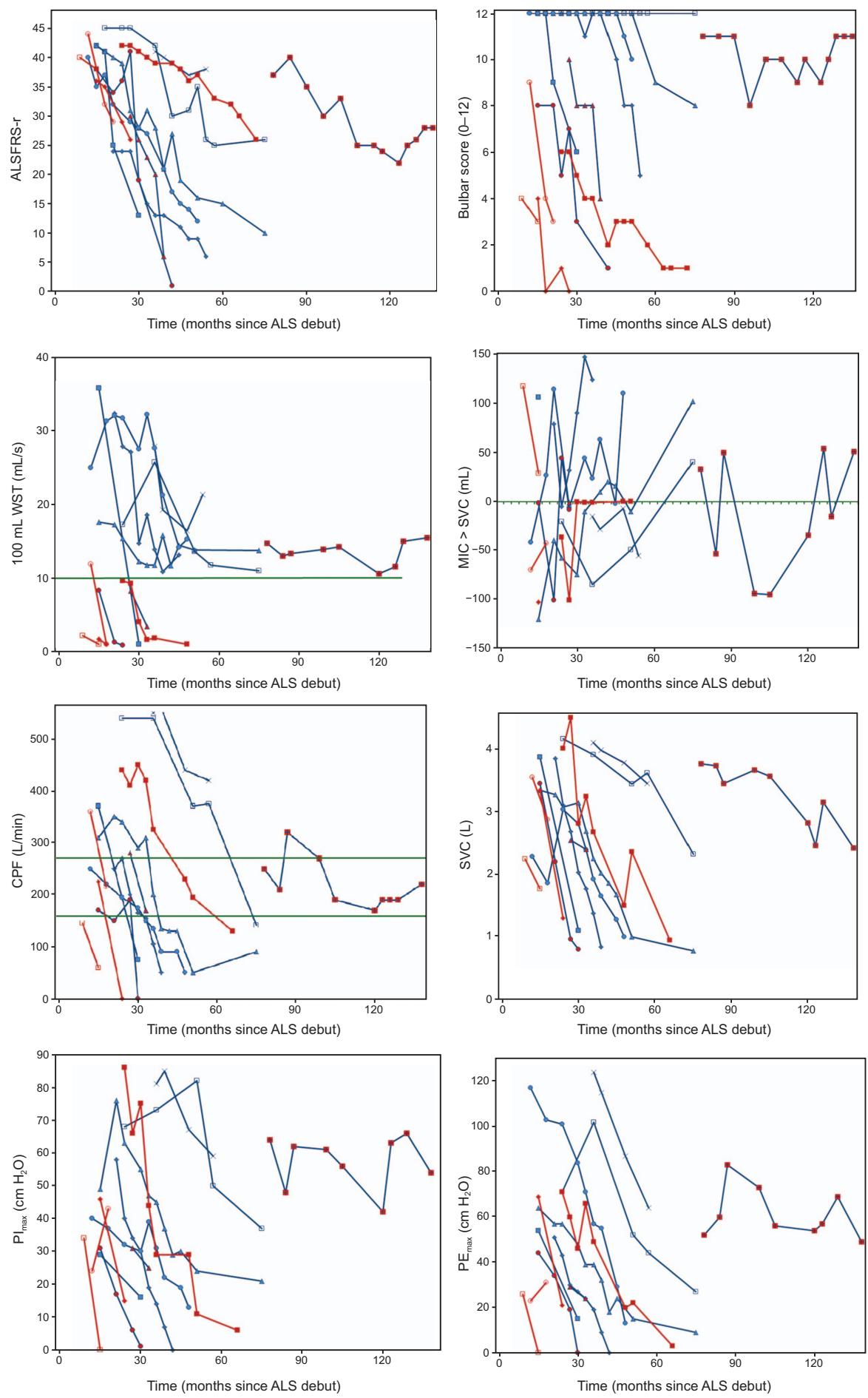

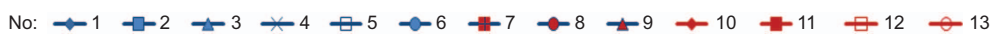

Fig. 1. Line plots of subjects' neurological and respiratory characteristics during the study follow-up. The zero line for MIC $>$ SVC indicates preserved ability to air stacking. The green line for WST indicates dysphagia. For cough peak flow, the upper line (270 L/min) in a stable condition indicates the risk of ineffective spontaneous cough in ALS during acute episodes (from Reference 15), and the lower line (160 $\mathrm{L} / \mathrm{min}$ ) indicates ineffectiveness of cough to expulse respiratory secretions in ALS patients (from Reference 19). Red lines indicate subjects with bulbar onset; blue lines indicate subjects with spinal onset, and blue lines with red dots indicate subjects with spinal onset but bulbar symptoms at study entry. ALS = amyotrophic lateral sclerosis; ALSFRS-r = ALS Functional Rating Scale-revised; WST = water swallow test; $\mathrm{MIC}=$ maximal insufflation capacity; $\mathrm{SVC}=$ slow vital capacity; $\mathrm{CPF}=$ cough peak flow; $\mathrm{PI}_{\max }=$ maximum inspiratory pressure; $\mathrm{PE}_{\max }=$ maximum expiratory pressure. 


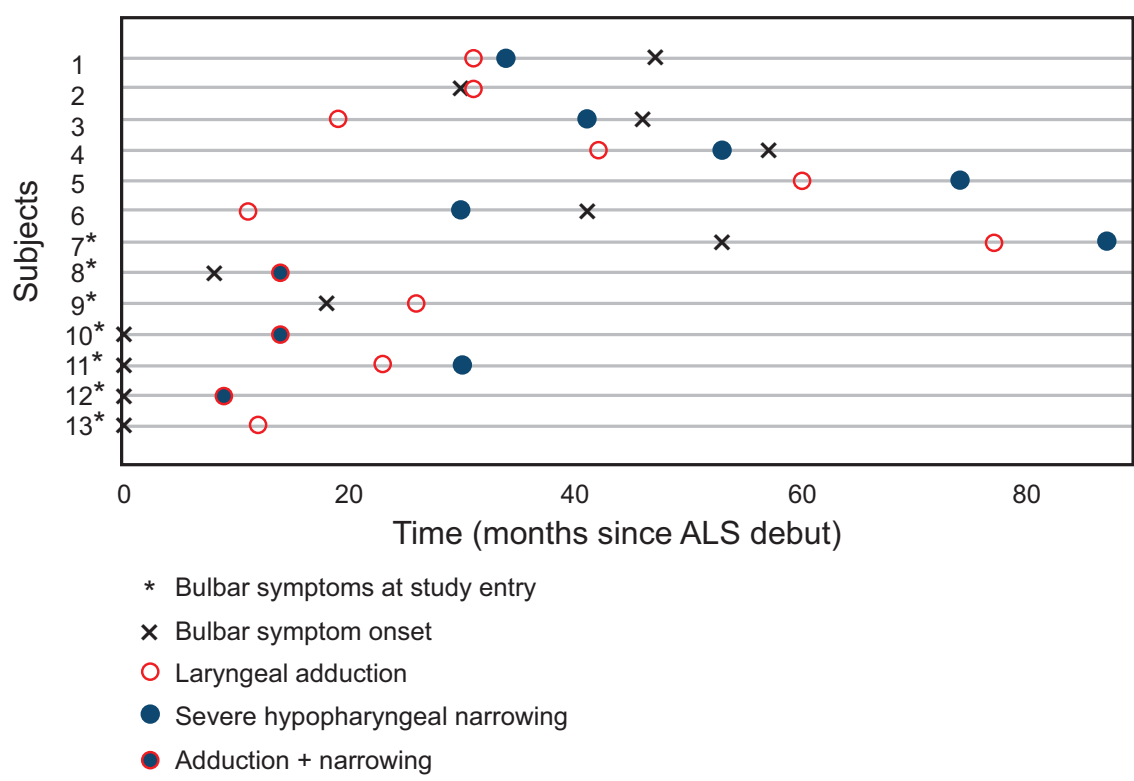

Fig. 2. Dot chart visualizing the appearance of the main laryngeal adverse responses observed during mechanical in-exsufflation and the onset of bulbar involvement $(N=13)$. Laryngeal adduction is during insufflation, and severe hypopharyngeal narrowing is during exsufflation. ALS = amyotrophic lateral sclerosis.

Table 3. Subject Characteristics at First Examination, When the Adverse Laryngeal Events Were Observed, and at Last Follow-Up

\begin{tabular}{|c|c|c|c|c|c|c|c|}
\hline & $\begin{array}{l}\text { First Examination } \\
\quad(n=13)\end{array}$ & $\begin{array}{c}\text { AEF Closure } \\
(n=13)\end{array}$ & $\begin{array}{l}\text { Retroflex EG } \\
\quad(n=7)\end{array}$ & $\begin{array}{c}\text { TVF Closure } \\
(n=8)\end{array}$ & $\begin{array}{c}\text { Backward TB } \\
(n=12)\end{array}$ & $\begin{array}{l}\text { Severe HP Constriction } \\
\quad(n=11)\end{array}$ & $\begin{array}{c}\text { Last Examination } \\
\qquad(n=13)\end{array}$ \\
\hline Months since ALS symptom onset, $n$ & $15(9-77)$ & $23(9-77)$ & $33(9-77)$ & $31(11-77)$ & $26(11-87)$ & $31(9-87)$ & $39(15-136)$ \\
\hline ALSFRS-r & $38.5(5.9)$ & $33.6(10.4)$ & $37.9(5.1)$ & $30.5(10.6)$ & $34.3(8.6)$ & $33.4(9.4)$ & $19.9(12.5)$ \\
\hline Bulbar score & $9.5(3.1)$ & $9.1(3.1)$ & $11(1.7)$ & $10.6(2.1)$ & $9.4(3.40)$ & $9.2(3.2)$ & $5.4(4.1)$ \\
\hline Respiratory score & $10.2(3.1)$ & $10.2(3.2)$ & $9.9(3.4)$ & $9.4(3.2)$ & $9.8(2.8)$ & $9.8(3.7)$ & $5.8(4.6)$ \\
\hline Cough peak flow, $\mathrm{L} / \mathrm{min}$ & $319(129)$ & $265(119)$ & $322(186)$ & $240(114)$ & $275(111)$ & $245(120)$ & $125(114)$ \\
\hline SVC, L & $3.4(0.7)$ & $2.9(1.0)$ & $3.6(0.6)$ & $2.8(1.0)$ & $3.2(0.8)$ & $2.8(0.7)$ & $1.7(0.9)$ \\
\hline $\mathrm{PI}_{\max }, \mathrm{cm} \mathrm{H}_{2} \mathrm{O}$ & $49(21)$ & $43(23)$ & $63(23)$ & $46(22)$ & $46(21)$ & $41(18)$ & $22(20)$ \\
\hline $\mathrm{PE}_{\text {max }}, \mathrm{cm} \mathrm{H}_{2} \mathrm{O}$ & $61(31)$ & $48(29)$ & $76(28)$ & $61(40)$ & $59(29)$ & $46(25)$ & $20(20)$ \\
\hline SNIP, $\mathrm{cm} \mathrm{H}_{2} \mathrm{O}$ & $42(18)$ & $32(19)$ & $40(18)$ & $36(25)$ & $35(14)$ & $35(15)$ & $18(23)$ \\
\hline MIC $>$ SVC, L & $0.26(0.44)$ & $0.26(0.46)$ & $0.13(0.20)$ & $0.23(0.34)$ & $0.21(0.39)$ & $0.32(0.53)$ & $0.29(0.36)$ \\
\hline WST, $\mathrm{mL} / \mathrm{s}$ & $16.3(11.0)$ & $11.3(7.3)$ & $16.3(10.7)$ & $14.0(7.3)$ & $14.3(9.6)$ & $11.2(7.8)$ & $7.2(7.8)$ \\
\hline
\end{tabular}

Values are given as mean (SD), except months from ALS symptom onset, given as median (range).

$\mathrm{AEF}=$ aryepiglottic folds

$\mathrm{EG}=$ epiglottis

TVF $=$ true vocal folds

$\mathrm{TB}=$ tongue base

$\mathrm{HP}=$ hypopharyngeal

ALS $=$ amyotrophic lateral sclerosis

ALSFRS-r $=$ ALS Functional Rating Scale-revised

$\mathrm{SVC}=$ slow vital capacity

$\mathrm{PI}_{\max }=$ maximum inspiratory pressure

$\mathrm{PE}_{\max }=$ maximum expiratory pressure

SNIP $=$ sniff nasal inspiratory pressure

MIC $>$ SVC $=$ maximal insufflation capacity over slow vital capacity

WST $=100-\mathrm{mL}$ water swallow test

laryngeal events were first observed during the MI-E. Including or excluding case no. 7 (slow progression) did not significantly alter these results (data not shown).

\section{MI-E Responses at the Glottic Level}

Adduction of true vocal folds during insufflation (Table 1) developed with disease progression in 8 of 9 subjects with spinal onset (Fig. 3A, Table 3). This occurred prior to other bulbar symptoms at median (range) 31 (11-77) months after ALS debut compared to 47 (18-57) months for other bulbar symptoms $(P=.046)$, and this was more prominent with a treatment pressure of $50 \mathrm{~cm} \mathrm{H}_{2} \mathrm{O}$ than with lower pressures. Observation of the glottic laryngeal level during insufflation was successful in subjects with spinal onset, but this was generally not possible in subjects 

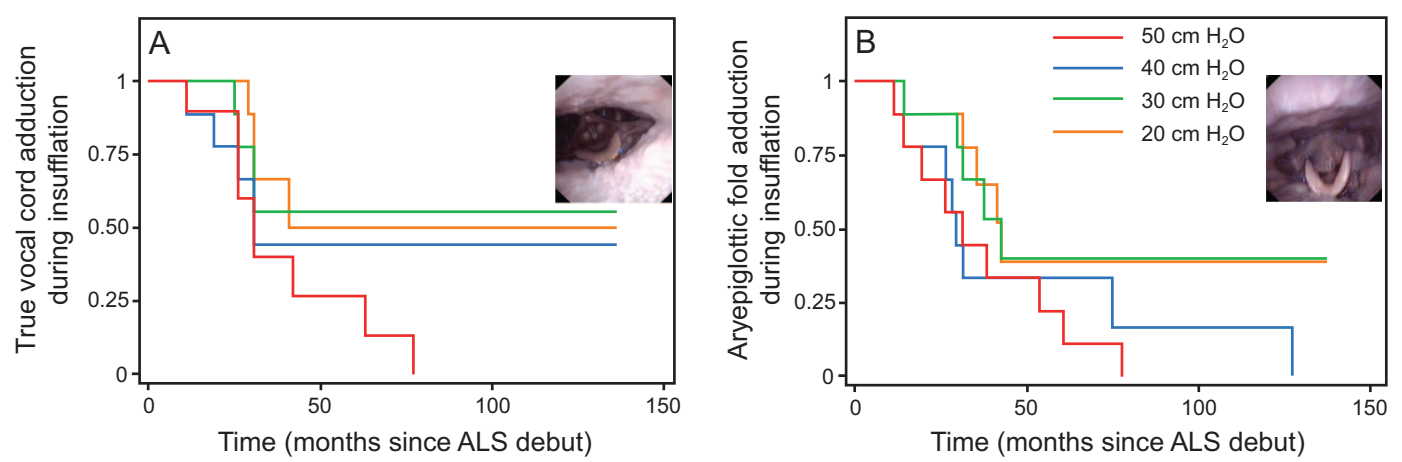

Fig. 3. Kaplan-Meier survivor function for events of adduction during MI-E insufflation of (A) true vocal folds in spinal-onset ALS ( $n=9$ ) and (B) aryepiglottic folds in all subjects $(N=13)$, at the insufflation pressures of $+50,40,30$, and $20 \mathrm{~cm}_{2} \mathrm{O}$.
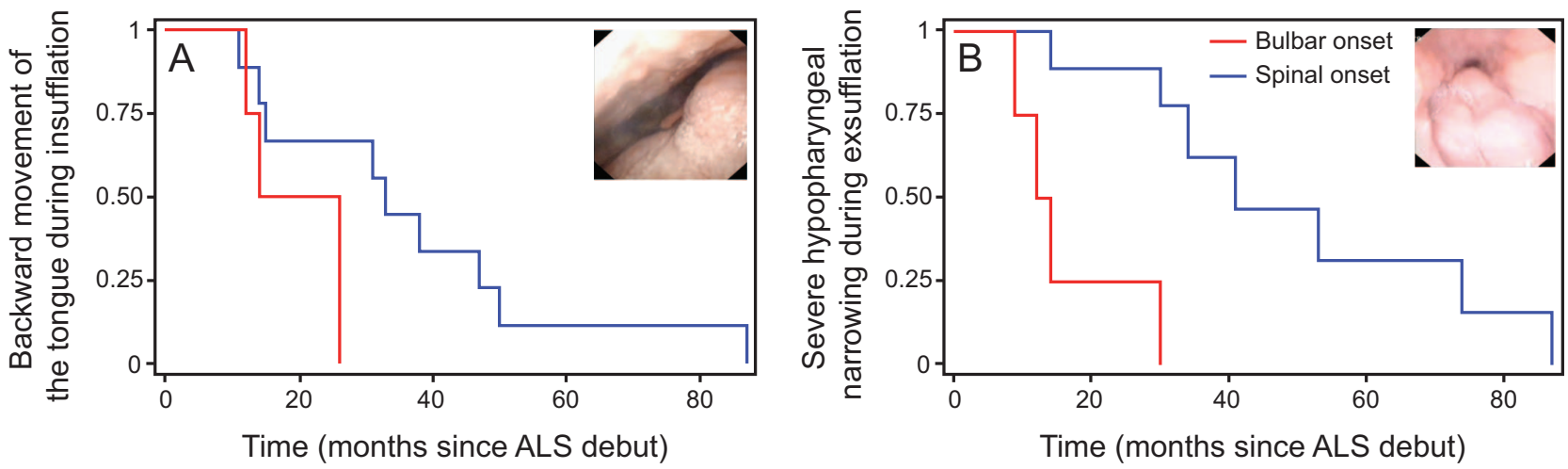

Fig. 4. Kaplan-Meier survivor function in subjects with spinal onset $(n=9)$ and bulbar onset $(n=4)$. The $y$-axis depicts the fraction of the group without the event in question. ALS = amyotrophic lateral sclerosis.

with bulbar-onset ALS because adducted aryepiglottic folds obscured the view of the true vocal folds.

\section{MI-E Responses at the Supraglottic Level}

Aryepiglottic fold adduction during insufflation (Table 1) was observed in all subjects during follow-up, independent of spinal-onset or bulbar-onset presentation (Table 3). All subjects with bulbar symptoms at study entry had aryepiglottic fold adduction from the first examination with insufflation pressures of +40 to $+50 \mathrm{~cm} \mathrm{H}_{2} \mathrm{O}$. One of 6 subjects with spinal onset and no bulbar symptoms at study entry had aryepiglottic fold adduction at first examination with insufflation pressures of $+50 \mathrm{~cm} \mathrm{H}_{2} \mathrm{O}$. In the remaining 5 subjects, this occurred at $50 \mathrm{~cm} \mathrm{H}_{2} \mathrm{O}$ at median (range) $38(19-60)$ months after the ALS debut compared to $47(30-57)$ months for other bulbar symptoms $(P=.046)$. In 4 of 6 subjects, we observed adduction at $40 \mathrm{~cm} \mathrm{H}_{2} \mathrm{O}$ after 29 months after ALS debut, at $30 \mathrm{~cm} \mathrm{H}_{2} \mathrm{O}$ after 37 months after ALS debut, and at $20 \mathrm{~cm} \mathrm{H}_{2} \mathrm{O}$ after 41 months after ALS debut, respectively. Time from ALS debut to development of this adverse laryngeal event for all subjects was overall shorter in subject with bulbar onset than in those with spinal onset $(P=.02)$ (Fig. 3B). Ret- roflex movement of the epiglottis during insufflation (Table 1) was observed in 7 of 13 cases (5 with spinal onset and 2 with bulbar onset) regardless of insufflation pressures during the follow-up periods (Table 3 ). This adverse laryngeal event seemed to occur independent of bulbar involvements. Thus, in subjects with bulbar symptoms at inclusion, this adverse laryngeal event was observed during the first examination in 4 subjects, whereas in subjects with spinal-onset ALS with no bulbar symptoms at study entry, it evolved in 3 cases at a median 35 months after ALS debut and always prior to the onset of other bulbar symptoms. In most subjects whose MI-E treatment was complicated by swallowing, this seemed to be associated with retroflex movement of epiglottis (Video 2, see the supplementary materials at http://www.rcjournal.com).

\section{MI-E Response at the Tongue Base and at the Hypopharyngeal Level}

Backward movement of the tongue base during insufflation (Table 1) was observed in 12 of 13 participants, regardless of insufflation pressures (Fig. 4A, Table 3), and the timing of this response in relation to ALS debut did not differ between subjects with bulbar-onset ALS versus spi- 
Table 4. Optimal MI-E Settings* and Relevant Case Characteristics

\begin{tabular}{|c|c|c|c|c|c|c|}
\hline & Case 2 & Case 3 & Case 5 & Case 6 & Case 7 & Case 13 \\
\hline Months since ALS symptom onset & 30 & 72 & 74 & 51 & 136 & 20 \\
\hline Cough peak flow, $\mathrm{L} / \mathrm{min}$ & 75 & 90 & 141 & 50 & 220 & 215 \\
\hline SVC, L & 1.1 & 0.8 & 2.3 & 1.0 & 2.4 & 2.9 \\
\hline $\mathrm{MIC}>\mathrm{SVC}$ & No & Yes & Yes & Yes & Yes & No \\
\hline Bulbar score & 6 & 8 & 12 & 10 & 11 & 3 \\
\hline Cough coordination with MI-E cycles & Rigid/Narrow & Narrow & Swallows & Rigid/Swallows & Rigid/Swallows & $\begin{array}{l}\text { Manage no } \\
\text { insufflation }\end{array}$ \\
\hline Patient-triggered insufflation & On & On & On & On & On & ND \\
\hline Insufflation pressure, $\mathrm{cm} \mathrm{H}_{2} \mathrm{O}$ & +15 & +25 & +25 & +40 & +25 & ND \\
\hline Insufflation flow & Low & High & Low & Medium & Medium & ND \\
\hline Insufflation time, $\mathrm{s}$ & 3.5 & 3.0 & 3.0 & 2.0 & 3.0 & ND \\
\hline Exsufflation pressure, $\mathrm{cm} \mathrm{H}_{2} \mathrm{O}$ & -35 & -40 & -40 & -40 & -40 & -40 \\
\hline Exsufflation time, s & 1.0 & 2.0 & 1.7 & 2.0 & 2.0 & Manual \\
\hline Oscillation & Off & Off & Off & On/Off & On/Off & Off \\
\hline Frequency, $\mathrm{Hz}$ & ND & ND & ND & 10 & 10 & ND \\
\hline Amplitude, $\mathrm{cm} \mathrm{H}_{2} \mathrm{O}$ & ND & ND & ND & 10 & 10 & ND \\
\hline Recommended MI-E cough cycles & 1 & $3-6$ & $3-6$ & 1 & 1 & 1 \\
\hline $\begin{array}{l}\text { * Optimal settings were noted at the subject's last tr } \\
\text { ALS = amyotrophic lateral sclerosis } \\
\text { SVC = slow vital capacity } \\
\text { MIC = maximal insufflation capacity } \\
\text { MI-E = mechanical insufflation-exsufflation } \\
\text { ND = no data }\end{array}$ & asal fiberoptic exami & & & & & \\
\hline
\end{tabular}

nal-onset ALS [median (range) 15 (12-26) months versus 33 (11-87) months, respectively $(P=.17)]$. All subjects without bulbar symptoms at inclusion developed this adverse laryngeal event before they developed any other bulbar symptoms [median (range) 35 (11-50) versus 46 (3057) months, respectively $(P=.028)]$.

Constriction of the hypopharynx during exsufflation was observed in all subjects regardless of the presence of bulbar symptoms. A severe hypopharyngeal narrowing during exsufflation was observed in 11 of 13 subjects [7 spinal-onset and 4 bulbar-onset (Fig. 4B and Table 3)]. In subjects with spinal-onset ALS, this evolved at a median (range) $41(14-87)$ months after ALS debut and prior to onset of other bulbar symptoms $44(8-57)$ $(P=.043)$, respectively. The results of the log-rank test showed a significant difference in the risk of severe hypopharyngeal narrowing during exsufflation between subjects with bulbar-onset or spinal-onset ALS $(P=.002)$. Severe hypopharyngeal narrowing appeared after development of backward movement of the tongue base $(P=.02)$, true vocal fold adduction $(P=.028)$, and aryepiglottic fold adduction $(P=.035)$.

\section{Exploratory Use of Modified MI-E Settings for Home Treatment}

In 1 subject with bulbar-onset ALS and 5 subjects with spinal-onset ALS, individually titrated settings were as- sessed with transnasal fiberoptic laryngoscopy when these subjects attended their scheduled out-patient visits. A total of 45 film clips were analyzed from 19 visits.

The optimal MI-E settings for these 6 cases according at their last transnasal fiberoptic examination, along with relevant case characteristics, are presented in Table 4. See Videos 3 and 4 for 2 cases using MI-E first with pressures of $\pm 40 \mathrm{~cm} \mathrm{H}_{2} \mathrm{O}$ and thereafter with individually customized treatment (see the supplementary materials at http:// www.rcjournal.com). Asymmetric treatment pressures with lower insufflation pressures and flows were observed to provide less adduction in the larynx, both at the supraglottic and glottic level, with more appropriate laryngeal responses to insufflation at least in some, if not all, cough cycles.

The use of one cough cycle at a time, allowing a pause prior to the next insufflation, and instructions to actively inhale prior to insufflation, was observed to induce better cough synchronization, particularly in cases of a retroflex epiglottis or spasticity at the laryngeal level. The use of patient-triggered insufflation did not seem to prevent swallowing reflexes. The use of oscillation promoted a variety of laryngeal movements, and both severe adduction and clear abduction in both insufflation and exsufflation were observed, although insufflation oscillation of $10 \mathrm{~Hz}$ appeared to create a more stable laryngeal opening in some cases compared to no oscillation. 


\section{Discussion}

This is the first prospective and longitudinal study of laryngeal responses to mechanically assisted cough therapy applied in subjects with progressing ALS. The study indicates that external pressures generated with MI-E, especially during insufflation, can promote airway adduction at both pharyngeal and laryngeal levels, and therefore can obstruct air flow and disrupt the effect of the treatment. This occurred prior to the development of clinically evident bulbar signs, and supraglottic structures were most vulnerable. Initially, laryngeal adduction occurred at the highest insufflation pressures, but it also occurred at lower pressures as the disease progressed. Individually tailored MI-E settings, carefully applied as a subject deteriorates, seemed to prolong successful use of noninvasive treatment.

\section{Strengths and Weaknesses}

The major strengths of this study were the prospective longitudinal design with successful application of serial examinations utilizing comprehensive equipment for up to 5 years of progression in 13 subjects with a rare and fatal disease, with only 2 of 20 eligible patients actively declining. The issues raised by this explorative study are highly important to patients in great distress and should be systematically addressed during their follow-up at institutions larger than ours. One weakness of this study is that retrieval of data could not be done continuously, rather only at pre-set out-patient appointments. Moreover, the small number of participants complicates statistical handling of the data, particularly interpretations of the negative findings. ${ }^{18}$ Furthermore, this study is by its nature explorative, and the validity and reliability of the findings as well as our interpretations have not yet been specifically targeted. These are issues that need to be addressed in future studies. However, as adverse laryngeal events consistently preceded other signs of bulbar involvement in cases with no bulbar symptoms at inclusion, the main message from this study stands out as solid. To avoid bothersome, futile, or even counterproductive handling of these vulnerable patients, we need proper and feasible methods that ensure optimal and extended use of noninvasive respiratory treatment. Various measures of lung function have been suggested to this end, such as cough peak flow, ${ }^{15,19}$ respiratory muscle strength, ${ }^{20}$ and the relationship between maximum insufflation capacity and slow vital capacity. ${ }^{21}$ Additionally, various neurological scoring systems and clinical signs that indicate bulbar involvement are used as signals to use caution. By observing medial collapse of laryngeal structures during insufflation before the appearance of these signs and symptoms, we question the use of such signs and symptoms as primary indications and in- stead suggest direct assessment of the larynx in patients who are difficult to treat. This is supported by Sayas Catalan et al, ${ }^{22}$ who recently showed that use of video-recorded laryngoscopy in NIV titration leads to fewer obstructive events during NIV in subjects with upper-airway obstruction. In addition, Georges et $\mathrm{al}^{23}$ inspected the larynx with transnasal fiberoptic laryngoscopy during NIV in 11 subjects with ALS and reported heterogeneous laryngeal response patterns. Thus, transnasal fiberoptic laryngoscopy can be a valuable tool during a variety of respiratory therapeutic interventions in selected patients who do not respond as expected.

\section{ALS Affects Laryngeal Function}

The larynx is a highly complex organ with muscles that are under both voluntary and reflex neural control. Important functions such as phonation, swallowing, breathing, and coughing are synchronized with a shared innervation. ${ }^{1,24,25}$ Stimulation with positive airway pressure (PAP) has been used by otolaryngologists to provoke laryngeal reflex activities ${ }^{26}$ leading to both laryngeal closure ${ }^{27}$ and swallowing. ${ }^{28} \mathrm{We}$ observed both of these responses in our subjects, possibly due to these reflex responses being elicited by the MI-E. In ALS, degeneration of corticobulbar pathways or brainstem neurons disturb both voluntary and reflectory muscular efforts, leading to compound clinical problems, such as respiratory complications and swallowing disturbances. ${ }^{1,24,25}$ Both upper and lower motor neuron failure is possible, as are spastic or hypotonic muscular responses, leading to variable and complex clinical consequences that are difficult to predict. Thus, laryngeal dysfunction has been suggested to occur both before and after the onset of other bulbar symptoms in ALS., ${ }^{1,29}$ This longitudinal study showed us that the larynx failed to respond adequately to externally applied positive pressures in all subjects but one before this could be predicted by other signs generally used to signal bulbar involvement.

\section{ALS Patients Cough Differently Than Other Neuromuscular Patients}

Effective cough is absolutely crucial to respiratory health. It is a forceful and vigorous maneuver that requires muscle strength and complex neurological interactions. A deep inspiration is followed by a compressive phase involving firm closure of the glottis and then active and forceful expiration with glottic opening (generating the cough peak flow), possibly followed by a varying number of sequential glottic closures and openings, which thereby increase the number of cough air flow spikes. ${ }^{30,31}$ Chaudri et al ${ }^{32}$ demonstrated that bulbar subjects were unable to generate cough air flow spikes, possibly explaining their ineffective cough. Our observations support altered cough patterns in 
ALS (eg, less expulsive, long drawn, and less synchronized at the laryngeal level). Reflex triggering of swallowing by the PAP applied by the MI-E may further complicate these matters.

In sum, rapid MI-E cycles may be challenging or impossible to handle for patients with ALS. It seems reasonable that successful MI-E requires that the larynx is reset after exsufflation and that possible swallowing or closure reflexes have been brought to an end before the next insufflation. An increased time interval between exsufflation and insufflation, or the use of only 1 cough cycle at a time, might thus be more appropriate to prepare the larynx for the next insufflation.

\section{Treatment Pressures}

As alluded to by Simonds, ${ }^{33}$ patients with bulbar ALS may not fail their MI-E, but instead the therapy may in fact have failed the patients due to erroneously applied settings. Until recently, high MI-E pressure settings have generally been considered to be most effective for neuromuscular patients, ${ }^{34,35}$ and most studies and clinicians apply settings of $\pm 40 \mathrm{~cm} \mathrm{H}_{2} \mathrm{O}$ or higher. ${ }^{36-38}$ Our findings indicate that in ALS, high pressures were the most provocative and most likely to cause adverse responses, and that such responses were difficult to predict based on other clinical signs or symptoms. Based on these observations, treatment pressures as high as $50 \mathrm{~cm} \mathrm{H}_{2} \mathrm{O}$ should probably be avoided in challenging cases of ALS, especially if fiberoptic laryngoscopy is not available. Insufflation pressures that are too high seem to be counterproductive because they may lead to laryngeal closure and thereby lower instead of higher insufflation volumes. Increasing the insufflation time instead of the insufflation pressure is probably be a more feasible way of achieving sufficient insufflation volumes. These findings agree with those of Senent et al, ${ }^{39}$ who used a ventilator to show that a positive pressure of $30 \mathrm{~cm} \mathrm{H}_{2} \mathrm{O}$ in fact produced higher cough peak flow than what was achieved by using MI-E with $\pm 40 \mathrm{~cm} \mathrm{H}_{2} \mathrm{O}$. These complex relationships may explain the diverging results that are reported in studies of subjects with bulbar-onset ALS, where MI-E has been shown both to fail $^{4}$ and to succeed ${ }^{39,40}$ in producing the cough peak flow considered necessary for effective cough. ${ }^{41}$

Patients with ALS may require different approaches compared to patients with other neuromuscular disorders without involvement of muscles with bulbar innervation concerning the pressures applied with mechanically assisted cough or NIV. ${ }^{33,42}$ It appears that high inspiratory pressures applied in subjects with inadequately innervated and uncoordinated larynx may lead to inspiratory laryngeal collapse and thus insufficient (or no) air entry to the lungs, which will therefore compromise any attempt to cough. Given the changing and deteriorating nature of ALS, with development of laryngeal responses being particularly difficult to predict, direct inspection of the larynx during ongoing treatment appears to be a simple and reasonable approach in patients with signs or symptoms suggesting treatment failure.

There are no guidelines for timing of possible tracheostomy if desired in ALS. ${ }^{43}$ We have provided data that may benefit ALS patients in that noninvasive treatment can be prolonged, potentially postponing the need to consider tracheostomy.

\section{Careful Application of Individualized MI-E Settings May Prolong Successful Use of Noninvasive Treatment}

A secondary aim of this study was to explore whether the use of modified MI-E settings could possibly succeed in keeping the laryngeal inlet open during insufflation for a prolonged period of time in subjects with deteriorating ALS. The applied modifications were partly based on findings from the subjects of our study, and partly based on personal clinical experience and on theoretical reasoning from other published data. Mustfa et $\mathrm{al}^{5}$ showed that exsufflation alone could produce higher cough peak flow than insufflation alone, which supports the use of asymmetrical cough support where only exsufflation is applied after a spontaneous deep inspiration in subjects with sufficient vital capacity.

We found evidence suggesting that hypopharyngeal constriction occurred later in disease progression than laryngeal adduction during insufflation, thus supporting the theory that an inability to fill the lungs with insufflation can create a vacuum effect during subsequent exsufflation and thereby aggravate hypopharyngeal narrowing. ${ }^{9}$ This emphasizes the importance of keeping the larynx open during insufflation and supports the use of lower insufflation than exsufflation pressures combined with careful use of lower insufflation flows.

Moreover, we found that asymmetrical settings with lower insufflation pressures and flows and applying one cough cycle at a time allowing for a pause prior to the next insufflation, as well as instructions to actively inhale prior to an insufflation, all appeared to be beneficial. Oscillation during insufflation may also contribute positively, whereas swallowing reflexes seemed more difficult to avoid, regardless of settings. While these findings are obviously highly explorative, they represent an attempt to address these matters with verifiable methods and outcomes and should be targeted in future research.

\section{Conclusions}

Noninvasive use of MI-E is challenging in patients with ALS. It is possible, however, to effectively assist airway 
clearance, at least for a time during the disease progression, by managing each patient with individual follow-up, perhaps with regular home visits to those with advanced disease and with the expectation that settings and interventions need to be adjusted as the disease progresses. This study demonstrated that laryngeal malfunction precedes other signs and symptoms of bulbar involvement, further complicating assessment and handling. Flexible laryngoscopy appears to be a reasonable approach for patients who do not respond to treatment as expected.

\section{ACKNOWLEDGMENTS}

The authors extend many thanks to the study participants and their caregivers for their participation in this study. We are also very grateful to medical photographer Thor-Andre Ellingsen for valuable help with the video recordings and editing of film clips, to nurses Gunvor Mo Norstein and Marit Arnevik Renså for coordinating the ALS clinic and helping run examinations, to otolaryngologists Magnus Hilland and Lorenz Sandvik for performing several TFL examinations, and to neurologist Tiina Rekand to contributing the neurological assessments.

\section{REFERENCES}

1. Hadjikoutis S, Wiles CM. Respiratory complications related to bulbar dysfunction in motor neuron disease. Acta Neurol Scand 2001; 103(4):207-213

2. Louwerse ES, Visser CE, Bossuyt PM, Weverling GJ. Amyotrophic lateral sclerosis: mortality risk during the course of the disease and prognostic factors. The Netherlands ALS Consortium. J Neurol Sci 1997;152(suppl 1):S10-S17.

3. Homnick DN. Mechanical insufflation-exsufflation for airway mucus clearance. Respir Care 2007;52(10):1296-1305.

4. Sancho J, Servera E, Diaz J, Marin J. Efficacy of mechanical insufflation-exsufflation in medically stable patients with amyotrophic lateral sclerosis. Chest 2004;125(4):1400-1405.

5. Mustfa N, Aiello M, Lyall RA, Nikoletou D, Olivieri D, Leigh PN, et al. Cough augmentation in amyotrophic lateral sclerosis. Neurology 2003;61(9):1285-1287.

6. Farrero E, Prats E, Povedano M, Martinez-Matos JA, Manresa F, Escarrabill J. Survival in amyotrophic lateral sclerosis with home mechanical ventilation: the impact of systematic respiratory assessment and bulbar involvement. Chest 2005;127(6):2132-2138.

7. Aboussouan LS, Khan SU, Meeker DP, Stelmach K, Mitsumoto H. Effect of noninvasive positive-pressure ventilation on survival in amyotrophic lateral sclerosis. Ann Intern Med 1997;127(6):450-453.

8. Bourke SC, Tomlinson M, Williams TL, Bullock RE, Shaw PJ, Gibson GJ. Effects of non-invasive ventilation on survival and quality of life in patients with amyotrophic lateral sclerosis: a randomised controlled trial. Lancet Neurol 2006;5(2):140-147.

9. Andersen T, Sandnes A, Brekka AK, Hilland M, Clemm H, Fondenes $\mathrm{O}$, et al. Laryngeal response patterns influence the efficacy of mechanical assisted cough in amyotrophic lateral sclerosis. Thorax 2017;72(3):221-229.

10. Brooks BR, on behalf of Subcommittee on Motor Neuron Diseases/Amyotrophic Lateral Sclerosis of the World Federation of Neurology Research Group on Neuromuscular Diseases and the El Escorial "Clinical Limits of Amyotrophic Lateral Sclerosis" Workshop Contributors. El Escorial World Federation of Neurology criteria for the diagnosis of amyotrophic lateral sclerosis. J Neurol Sci 1994;124(suppl):96-107.
11. Brooks BR, Miller RG, Swash M, Munsat TL, on behalf of World Federation of Neurology Research Group on Motor Neuron D. El Escorial revisited: revised criteria for the diagnosis of amyotrophic lateral sclerosis. Amyotroph Lateral Scler Other Motor Neuron Disord 2000;1(5):293-299.

12. Cedarbaum JM, Stambler N, Malta E, Fuller C, Hilt D, Thurmond B, et al. The ALSFRS-R: a revised ALS functional rating scale that incorporates assessments of respiratory function. J Neurol Sci 1999; 169(1-2):13-21.

13. Hughes TA, Wiles CM. Clinical measurement of swallowing in health and in neurogenic dysphagia. QJM 1996;89(2):109-116.

14. Wu MC, Chang YC, Wang TG, Lin LC. Evaluating swallowing dysfunction using a 100-ml water swallowing test. Dysphagia 2004; 19(1):43-47.

15. Sancho J, Servera E, Diaz J, Marin J. Predictors of ineffective cough during a chest infection in patients with stable amyotrophic lateral sclerosis. Am J Respir Crit Care Med 2007;175(12):1266-1271.

16. Andersen T, Sandnes A, Hilland M, Halvorsen T, Fondenes O, Heimdal $\mathrm{JH}$, et al. Laryngeal response patterns to mechanical insufflationexsufflation in healthy subjects. Am J Phys Med Rehabil 2013; 92(10):920-929.

17. Collett D. Modelling Survival Data in Medical Research. Boca Raton, FL: CRC Press Taylor \& Francis Group; 2014:548.

18. Bacchetti P, Leung JM. Sample size calculations in clinical research. Anesthesiology 2002;97(4):1028-1029.

19. Sancho J, Servera E, Banuls P, Marin J. Effectiveness of assisted and unassisted cough capacity in amyotrophic lateral sclerosis patients. Amyotroph Lateral Scler Frontotemporal Degener 2017;18(7-8):1-7.

20. Poponick JM, Jacobs I, Supinski G, DiMarco AF. Effect of upper respiratory tract infection in patients with neuromuscular disease. Am J Respir Crit Care Med 1997;156(2 Pt 1):659-664.

21. Bach JR, Mahajan K, Lipa B, Saporito L, Goncalves M, Komaroff E. Lung insufflation capacity in neuromuscular disease. Am J Phys Med Rehabil 2008;87(9):720-725.

22. Sayas Catalan J, Jimenez Huerta I, Benavides Manas P, Lujan M, Lopez-Padilla D, Arias Arias E, et al. Videolaryngoscopy with noninvasive ventilation in subjects with upper-airway obstruction. Respir Care 2017;62(2):222-230.

23. Georges M, Attali V, Golmard JL, Morelot-Panzini C, Crevier-Buchman L, Collet JM, et al. Reduced survival in patients with ALS with upper airway obstructive events on non-invasive ventilation. J Neurol Neurosurg Psychiatry 2016;87(10):1045-1050.

24. Terzi N, Orlikowski D, Aegerter P, Lejaille M, Ruquet M, Zalcman $\mathrm{G}$, et al. Breathing-swallowing interaction in neuromuscular patients: a physiological evaluation. Am J Respir Crit Care Med 2007;175(3): 269-276.

25. Plowman EK, Watts SA, Robison R, Tabor L, Dion C, Gaziano J, et al. Voluntary cough airflow differentiates safe versus unsafe swallowing in amyotrophic lateral sclerosis. Dysphagia 2016;31(3):383-390.

26. Ludlow CL. Laryngeal reflexes: physiology, technique, and clinical use. J Clin Neurophysiol 2015;32(4):284-293.

27. Bhabu P, Poletto C, Mann E, Bielamowicz S, Ludlow CL. Thyroarytenoid muscle responses to air pressure stimulation of the laryngeal mucosa in humans. Ann Otol Rhinol Laryngol 2003;112(10): 834-840.

28. Theurer JA, Bihari F, Barr AM, Martin RE. Oropharyngeal stimulation with air-pulse trains increases swallowing frequency in healthy adults. Dysphagia 2005;20(4):254-260.

29. van der Graaff MM, Grolman W, Westermann EJ, Boogaardt HC, Koelman H, van der Kooi AJ, et al. Vocal cord dysfunction in amyotrophic lateral sclerosis: four cases and a review of the literature. Arch Neurol 2009;66(11):1329-1333.

30. Von Leden H, Isshiki N. An analysis of cough at the level of the larynx. Arch Otolaryngol 1965;81:616-625. 


\section{LARYNGEAL Response to MI-E IN ALS}

31. Leith DE. The development of cough. Am Rev Respir Dis 1985; 131(5):S39-S42.

32. Chaudri MB, Liu C, Hubbard R, Jefferson D, Kinnear WJ. Relationship between supramaximal flow during cough and mortality in motor neurone disease. Eur Respir J 2002;19(3):434-438.

33. Simonds AK. Progress in respiratory management of bulbar complications of motor neuron disease/amyotrophic lateral sclerosis? Tho$\operatorname{rax} 2017 ; 72(3): 199-201$.

34. Sancho J, Servera E, Marin J, Vergara P, Belda FJ, Bach JR. Effect of lung mechanics on mechanically assisted flows and volumes. Am J Phys Med Rehabil 2004;83(9):698-703.

35. Gomez-Merino E, Sancho J, Marin J, Servera E, Blasco ML, Belda FJ, et al. Mechanical insufflation-exsufflation: pressure, volume, and flow relationships and the adequacy of the manufacturer's guidelines. Am J Phys Med Rehabil 2002;81(8):579-583.

36. Boitano LJ. Management of airway clearance in neuromuscular disease. Respir Care 2006;51(8):913-922.

37. Anderson JL, Hasney KM, Beaumont NE. Systematic review of techniques to enhance peak cough flow and maintain vital capacity in neuromuscular disease: the case for mechanical insufflation-exsufflation. Physical Therapy Reviews 2005;10:25-33.
38. Morrow B, Zampoli M, van Aswegen H, Argent A. Mechanical insufflation-exsufflation for people with neuromuscular disorders. Cochrane Database Syst Rev 2013;(12):CD010044.

39. Senent C, Golmard JL, Salachas F, Chiner E, Morelot-Panzini C, Meninger $\mathrm{V}$, et al. A comparison of assisted cough techniques in stable patients with severe respiratory insufficiency due to amyotrophic lateral sclerosis. Amyotroph Lateral Scler 2011;12(1):2632.

40. Trebbia G, Lacombe M, Fermanian C, Falaize L, Lejaille M, Louis A, et al. Cough determinants in patients with neuromuscular disease. Respir Physiol Neurobiol 2005;146(2-3):291-300.

41. Bach JR, Saporito LR. Criteria for extubation and tracheostomy tube removal for patients with ventilatory failure. A different approach to weaning. Chest 1996;110(6):1566-1571.

42. Simonds AK. Home mechanical ventilation: an overview. Ann Am Thorac Soc 2016;13(11):2035-2044.

43. Ceriana P, Surbone S, Segagni D, Schreiber A, Carlucci A. Decisionmaking for tracheostomy in amyotrophic lateral sclerosis (ALS): a retrospective study. Amyotroph Lateral Scler Frontotemporal Degener 2017;18(7-8):1-6. 